\title{
Regulation of the corticosteroid signalling system in rainbow trout HPI axis during confinement stress.
}

\author{
Kiilerich Pia ${ }^{1,{ }^{*}}$, Servili Arianna ${ }^{2}$, Péron Sandrine ${ }^{1}$, Valotaire Claudiane ${ }^{1}$, Goardon Lionel ${ }^{3}$, Leguen \\ Isabelle ${ }^{1}$, Prunet Patrick ${ }^{1,{ }^{*}}$
}

1 INRA, UR1037, Fish Physiology and Genomics, 35042 Rennes, France

2 Ifremer, Unité de Physiologie Fonctionnelle des Organismes Marins, LEMAR UMR 6539, BP 70, Plouzané 29280, France

3 INRA, UE937 Pisciculture expérimentale des Monts d'Arrée, 29450 Sizun, France

* Corresponding authors : Pia Kiilerich, email address : pkiilerich@bio.ku.dk ; Patrick Prunet, email addres : $\underline{\text { Patrick.prunet@inra.fr }}$

\begin{abstract}
:
This study aims to shed light on corticosteroid regulation of stress in teleost fish with focus on the corticosteroid signalling system. The role of the mineralocorticoid-like hormone 11-deoxycorticosterone $(D O C)$ in fish is still enigmatic, as is the function of the mineralocorticoid receptor, MR. Low plasma DOC levels and ubiquitous tissue distribution of MR question the physiological relevance of the mineralocorticoid-axis. Furthermore, the particular purpose of each of the three corticosteroid receptors in fish, the glucocorticoid receptors, GR1 and GR2, and the MR, is still largely unknown. Therefore we investigate the regulation of cortisol and DOC in plasma and mRNA levels of MR, GR1 and GR2 in the $\mathrm{HPI}$-axis tissue (hypothalamus, pituitary and interrenal gland) during a detailed confinement stress timecourse. Here we show a sustained up-regulation of plasma DOC levels during a confinement stress time-course. However, the low DOC levels compared to cortisol measured in the plasma do not favour an activity of DOC through MR receptors. Furthermore, we show differential contribution of the CRs in regulation and control of HPI axis activity following confinement stress. Judged by the variation of mRNA levels negative feedback regulation of cortisol release occurs on the level of the pituitary via MR and on the level of the interrenal gland via GR2. Finally, as a significant effect of confinement stress on CR expressions was observed in the pituitary gland, we completed this experiment by demonstrating that corticosteroid receptors (GR1, GR2 and MR) are co-expressed in the ACTH cells located in the adenohypophysis. Overall, these data suggest the involvement of these receptors in the regulation of the HPI axis activity by cortisol.
\end{abstract}




\section{Highlights}

- We have measured plasma cortisol and DOC levels in rainbow trout exposed to confinement stress during 7 days. We have measured glucocorticoid and mineralocorticoid receptors expression in hypothalamus, pituitary and interrenal and observed variable changes after confinement stress. We demonstrate that corticosteroid receptors are co-expressed in pituitary ACTh and GH cells in rainbow trout.

Keywords : Stress, Rainbow trout, Confinement, Cortisol, DOC, MR, GR1, GR2 H, PI-axis 


\section{Introduction}

Glucocorticoids play an essential role in regulation of the stress response in all vertebrates (Mommsen et al., 1999). The piscine stress axis encompasses the hypothalamus, pituitary and the interrenal gland (head kidney), called the HPI-axis, with the glucocorticoid cortisol as signalling hormone (Wendelaar Bonga, 1997). The perception of a stressor is integrated in the hypothalamus, and signalled to the pituitary via the corticotrophin-releasing hormone (CHR). In response, adrenocorticotrophic hormone (ACTH) is released from the pituitary to the blood stream and effectuates cortisol release from the interrenal gland (Mommsen et al., 1999). In fish, cortisol is a ligand for two glucocorticoid receptors, GR1 and GR2 and a mineralocorticoid receptor, MR (reviewed by Prunet et al., 2006), which are present in all tissues investigated so far (Ducouret et al., 1995, Bury et al., 2003, Sturm et al., 2005). In the absence of aldosterone in teleost, it is not yet known whether or not the MR-specific mineralocorticoid-like hormone 11-deoxycorticosterone (DOC) functions as a physiological relevant ligand for the MR (reviewed by Prunet et al., 2006). Cortisol affects the peripheral tissue such as gills, liver, heart, and muscle to increase energy consumption in order to provide increased oxygen uptake, metabolism, cardiac output and swimming activity, respectively, in order to cope with the stressor and mobilize energy for a fightor-flight response (Wendelaar Bonga, 1997, Mommsen et al., 1999). Whether all the fish gluco- and mineralocorticoid receptors are involved in this cortisol signalling still remains to be investigated. The control and release of cortisol from the HPI-axis in response to stressors is carefully governed by negative feedback regulation on all levels of the HPI-axis (Wendelaar Bonga, 1997, Mommsen et al., 1999, Carruth et al., 2002, Bernier et al., 2009). All three receptors are present in hypothalamus, pituitary and interrenal gland in different fish species (rainbow trout: Ducouret et al., 1995, Teitsma et al., 1998, Bury et al., 2003, Sturm et al,. 2005; kokanee salmon: Carruth et al., 2000; carp: Stolte et al., 2008a; tilapia: Pepels et al., 2004) and the GR has been demonstrated to be active in feedback regulation of cortisol release (reviewed by Wendelaar Bonga, 1997, reviewed by Mommsen et al., 1999, Carruth et al., 2002, reviewed by Bernier et al., 2009). Recent studies suggest such involvement of GR1, GR2 or MR in HPI axis regulation: For example, following short-term (1 day) slow-release cortisol implantation in rainbow trout, Teles et al. (2013) observed an increase in GR2 and MR expression in brain and interrenal gland, respectively. In Atlantic salmon parr exposed to acute stress, the three corticosteroid receptors were upregulated $1 \mathrm{~h}$ after exposure to an acute air exposure stress (Madaro et al., 2016). However, the specific roles of GR1 and GR2 in this regulation in fish are still largely unknown, as is the role of MR. The functionality 
of MR in the fish stress axis remains un-investigated, but studies in mammals demonstrated a role for MR in the brain in basal and stress-related regulation of the HPA-axis (reviewed by de Kloet, 2003). Additionally, it is becoming clearer that DOC also participates in signalling and regulation of stress in mammals (Park et al., 2017).

In this study, we applied a confinement stress during 7 days with the aims to characterize regulation of hormones and receptors in the corticosteroid signalling pathways in the HPI axis. Both plasma cortisol and DOC levels were analysed during 7 days in parallel to corticosteroid receptors expression in the hypothalamus, pituitary and interrenal gland. To complete this study, we also investigated the phenotypes of GR1, GR2 and MR mRNA-expressing cells in the pituitary gland. Overall, our data suggest that the MR signalling pathways could be involved in the stress response in rainbow trout.

\section{Materials and Methods.}

\subsection{Fish, confinement experiment and sampling.}

Experiments were performed at the PEIMA experimental farm (INRA, Sizun, France) having authorization for experimentation (agreement number: C29-447-02). All experimental procedures used in this study were carried out in accordance with the European Communities Council Directive of 24 November 1986 (86/609/EEC). Scientist in charge of the experimental procedure has authorization (P. Prunet, $n^{\circ} 07393$ ) to conduct animal experimentations in accordance with good animal practice delivered by the DDPP (Service de Protection et de Surveillance Sanitaire des Animaux et des Végétaux, french ministry of Agriculture). Three weeks before the start of the experiment 400 rainbow trout (Oncorhynchus mykiss, mixed sex, one year old, weight $112.8 \mathrm{~g} \pm 0.7$ SEM) were distributed in eight 300 liter tanks with 50 fish in each. Before the start of the experiment one fish from each tank ( 8 fish in total) were sampled to constitute the time zero control group. Subsequently, from each of seven tanks, 30 fish were transferred to a 300 liter tank (control group, fish density: $11 \mathrm{~g}$ fish/liter) and 16 fish were transferred to a confinement cage in a 300 liter tank (dimensions 19x29x30 cm, fish density: 111g fish/liter) (Fig. 1). Eight fish from either a confinement cage or control tank were sampled at 7 time-points (4 hours, 8 hours and 1, 2, 3, 4 and 7 days after transfer). . There was no repeated sampling in any of the tanks to avoid accumulated sampling stress.,

Fish were euthanized in high concentration of phenoxyethanol $(10 \mathrm{ml} / \mathrm{l})$ and blood was drawn from the caudal vein within 5 minutes. Blood samples were kept on ice until plasma was separated from 
whole blood by centrifugation. The fish were then killed by cutting the spine and interrenal gland, pituitary and hypothalamus were collected in separate tubes and immediately dry frozen in liquid nitrogen

\subsection{Analysis}

\subsubsection{Plasma cortisol and DOC}

Measurement of plasma cortisol and DOC were carried out using RIA methods previously described (Auperin et al., 1997; Kiilerich et al., 2011, respectively).

\subsubsection{RNA, primers and QPCR}

RNA was extracted from interrenal gland and hypothalamus using RNA II Nucleospin columns according to manufacturer's recommendations (Macherey-Nagel, Düren, Germany). RNA from pituitaries was extracted using $200 \mu \mathrm{l}$ TRIzol and a glycogen precipitation step according to manufacturer's recommendations (Invitrogen, Carlsbad, CA, USA). $1 \mu \mathrm{g}$ RNA was treated with 0.5 units RQ1 DNase (Promega, Madison, WI, USA) for $30 \mathrm{~min}$ at $37^{\circ} \mathrm{C}$ in a total volume of $21 \mu 1$, followed by $5 \mathrm{~min}$ at $75^{\circ} \mathrm{C}$ to inactivate the DNase. Reverse transcription was carried out with $1 \mu \mathrm{g}$ random primers, 200 units MMLV reverse transcriptase, $0.5 \mathrm{mM}$ dNTPs in the presence of 25 units RNasin RNase inhibitor (all chemicals from Promega) for 1 hour at $37^{\circ} \mathrm{C}$ in a total volume of $25 \mu 1$. cDNA samples were then diluted with 4 times with water and stored at $-20^{\circ} \mathrm{C}$ until analysis.

Semi-quantitative real time PCR was carried out with $5 \mu$ cDNA $(1 \mu 1$ for the normalization gene 18S) sample using ABI Fast SYBR master mix (Applied Biosystems, Carlsbad, CA, USA) on a StepOne Plus real time PCR machine (Applied Biosystems). Cycling conditions were $95^{\circ} \mathrm{C}$ for 20 sec for initial denaturation followed by 40 cycles of $95^{\circ} \mathrm{C}$ for $3 \mathrm{sec}$ and $60{ }^{\circ} \mathrm{C}$ for $30 \mathrm{sec}$ before a melt curve stage. Primers sequences were as follows: rtGR1 (GenBank n Z54210) forward 5'CCATCGTCAAGCGGGAAGAG-3', rtGR1 reverse 5'GGAACTCCACGCTAAGGGATTTATTC-3', rtGR2 (GenBank n AY495372) forward 5'CTCCGCTTTCTCCAGCAGCTA-3', rtGR2 reverse 5'-GTGAGCCACCCCGTAGTGACAG-3', rtMR (GenBank n ${ }^{\circ}$ NM_001124483) forward 5'-GAAACAGATGATCCGCGTGGT-3' and rtMR reverse 5'-TGGATCAGGGTGATTTGGTCCT-3', 18S (GenBank nº AF309412) rRNA forward 5'-CGGAGGTTCGAAGACGATCA

18S rRNA reverse 5'- TCGCTAGTTGGCATCGTTTATG-3'. 
Absolute quantification for direct comparison of mRNA transcript levels among the corticosteroid receptors were carried out as described in Kiilerich et al., 2011.

\subsubsection{Riboprobe synthesis}

Specific riboprobes were obtained using pCRII-TOPO Vector (Invitrogen, Life Technologies) containing cDNA of rainbow trout GR1, GRr2 and MR, previously exerted from pCMV5-rtGR1 (Ducouret et al., 1995), pCMV5-rtGR2 (Bury et al., 2003) and pCMV5-rtMR plasmids (Sturm et al., 2005).

Antisense and sense single-stranded mRNA probes were synthetized with DIG RNA labelling MIX (Roche, Indianapolis, IN) by transcription with T7 and SP6 polymerase (Promega, Madison, WI) on plasmids linearized by the NotI and BamHI restriction enzymes.

To confirm the specificity of the GR1, GR2 and MR probes, parallel series of slides were always hybridized with the correspondent sense RNA probes. This procedure yielded no signal (data not shown).

\subsubsection{In situ hybridization}

Six rainbow trout pituitaries collected from stressed and non-stress experimental groups were sectioned in serial transverse $12-\mu \mathrm{m}$-thick microtome sections and mounted onto poly-L-Lysinecoated slides. The protocol for in situ hybridization was performed as previously described (Servili et al., 2011) with modifications. Before hybridization, sections were dewaxed and rehydrated through decreasing concentrations of ethanol. They were washed in 0.1 M PBS (Phosphate Buffer Solution, $\mathrm{pH}$ 7.4) and post-fixed for $20 \mathrm{~min}$ in $4 \%$ paraformaldehyde solution. After washing in PBS, sections were treated with proteinase $\mathrm{K}$ for five minutes at $37^{\circ} \mathrm{C}[2 \mu \mathrm{g} / \mathrm{ml}$ in PBS], rinsed, and fixed in $4 \%$ paraformaldehyde. Sections were rinsed twice in $2 \mathrm{X}$ standard saline citrate (SSC). Hybridization was performed at $65^{\circ} \mathrm{C}$ in a humidified chamber using $100 \mu l$ hybridization buffer (2XSSC; $2.5 \%$ dextran sulfate; $50 \%$ deionized formamide; $5 \mathrm{X}$ Denhardt's solution; $50 \mu \mathrm{g} / \mathrm{ml}$ of yeast tRNA, pH 8.0; 4mM EDTA) containing the DIG-labeled probe $(2,5 \mu \mathrm{g} / \mathrm{ml})$. After hybridization, slides were rinsed in $2 \mathrm{X} \mathrm{SSC}$ at $65^{\circ} \mathrm{C}$, followed by two rinses in $2 \mathrm{XSSC} / 50 \%$ formamide. Final washing was made in decreasing concentration of SCC and sections were processed for immunodetection. The sections were washed for $10 \mathrm{~min}$ in $100 \mathrm{mM}$ Tris-HCl buffer, $150 \mathrm{mM} \mathrm{NaCl}$ ( $\mathrm{pH} 7.5$ ), incubated for $30 \mathrm{~min}$ in the same buffer (buffer 1) containing $0.5 \%$ blocking reagent and $0.2 \%$ Triton $\mathrm{X}-100$, and then incubated overnight at room temperature in 
alkaline phosphatase-conjugated sheep antibodies to digoxigenin diluted 1:2,000 in buffer 1. On the next day, sections were incubated in HNPP (2-hydroxy-3-naphtoic acid-2'-phenylanilide phosphate)/FastRED solution (Roche) for $2 \mathrm{~h}$. Finally, slides were coverslipped with Vectashield mounting medium containing 4',6-diamidino-2-phenylindole (DAPI) (Vector Laboratories, Burlingame, CA). They were observed under an epifluorescence microscope (Olympus BX51) equipped with a DP71 digital camera. Images were processed with the Olympus Analysis Cell software. Plates were assembled using Photoshop CS4.

\subsubsection{Combined GR1, GR2 and MR mRNA in situ hybridization and immunohistochemical} detection of growth hormone (GH), prolactin (PRL) and adrenocorticotropic hormone (ACTH) cells.

In order to identify the phenotypes of GR1, GR2 and MR mRNA-expressing cells in rainbow trout pituitary, a double labelling protocol was performed by combining in situ hybridization and immunohistochemistry. Once in situ hybridization was revealed, the sections were rinsed twice in PBS and in $0.2 \%$ Triton X-100 PBS (PBST). They were subsequently blocked for 45 minutes in PBST containing $0.5 \%$ blocking reagent at room temperature and incubated over night at room temperature using the following antibodies previously characterized and validated: rabbit antirainbow trout GH (1:1000), rabbit anti-rainbow trout-PRL (1:1000) (Prunet et al., 1985, Le Bail et al., 1991), rabbit anti-rainbow trout GR1 (1:1250) (Kiilerich et al., 2011), rabbit anti-rainbow trout MR (1:1500) (Kiilerich et al., 2011) and mouse anti-rat ACTH (1:1000) (Novus Biologicals, ref. NB600-1367). The next day, sections were washed three times in $0.2 \%$ Triton PBS and subsequently incubated with chicken anti-rabbit Alexa 488 or goat anti-mouse Alexa 488 (Invitrogen Molecular Probes, Eugene OR, USA) for $2 \mathrm{~h}$ at room temperature. All slides were washed in PBST and finally cover-slipped and mounted in Vectashield containing DAPI (Vector Laboratories) and observed in an epifluorescence microscope (Olympus BX51). The images were processed with the Olympus Analysis Cell B software and figures illustrated with Photoshop 7.0.

\subsubsection{Double immunohistochemistry for detection of MR and GR proteins}

For immunohistochemistry, 5 - $\mu$ m-thick microtome sections were deparaffined, rehydrated and treated for 1 hour at $80^{\circ} \mathrm{C}$ in citrate buffer ( $\mathrm{pH}$ 6) to unmask the epitopes. The sections were then rinsed in $0.2 \%$ Triton X-100 PBS (PBST) and incubated for 45 min. in PBST $+1 \%$ milk. For the first antibody (anti-MR), slides were exposed overnight at room temperature to rabbit anti-rainbow 
trout MR (1:3000). The next day, slides were rinsed with PBST and exposed to Alexia 594 chicken anti-rabbit (1:2000) (Invitrogen Molecular Probes, Eugene OR, USA) for 90 minutes at room temperature. For the second antibody (anti-GR1), after rinsing with PBST, slides were incubated overnight at room temperature with guinea pig anti-rainbow trout GR1 (1:1000) (Teisma et al., 1999). After washes with PBST, slides were exposed to Alexia 488 goat anti-guinea pig (1:2000) (Invitrogen Molecular Probes, Eugene OR, USA) for 90 minutes at room temperature. After incubation, slides were rinsed with PBST and covered by coverslip using Vectashield mounting medium with DAPI (Vector laboratories, USA). Observations were made with an epifluorescent microscope (Nikon Eclipse 90i). The images were processed with the NIS-Elements Microscope Imaging software and figures illustrated with Photoshop 7.0.

\subsection{Statistics}

Overall effects of confinement stress were analyzed using two-way ANOVA with time and treatment as variables followed by Bonferroni adjusted t-tests to compare values by time $(\mathrm{p}<0.05)$. One-way ANOVA with time as variable was employed to detect significant difference between absolute mRNA transcript levels within tissues for each condition. When necessary, data were transformed to obtain normal distribution. All data were analyzed using the GraphPad Prism 7 software (GraphPad Software, Inc. La Jolla, CA, USA).

\section{Results}

\subsection{Changes in plasma hormones levels}

There was an overall significant increase in both cortisol and DOC plasma levels in confined fish during the experiment (Fig. 2). There is an early peak in plasma DOC 4 hours after transfer followed by constitutive high DOC levels from day 1 to day 7 in confined fish compared to controls (Fig. 2A). Cortisol shows a maximum peak 1 day after transfer followed by a gradual decrease towards control levels (Fig. 2B). However, it is interesting to note that plasma DOC levels fluctuate in the range $10-50 \mathrm{pg} / \mathrm{ml}$ whereas cortisol increases from $2-10 \mathrm{ng} / \mathrm{ml}$ at basal levels up to $70-80$ $\mathrm{ng} / \mathrm{ml}$ at peak. 


\subsection{Transcript levels in hypothalamus, pituitary and interrenal gland.}

Absolut quantification of the three corticoid receptors was carried out in order to detect differences in expression level among them in the three different tissues (Table 1).

In hypothalamus, GR2 is expressed at a higher level than both GR1 (1.5-fold) and MR (8.5-fold), while GR1 level is 5.5-fold elevated compared to MR (Table 1). There are no significant differences in either MR, GR1 or GR2 mRNA levels in the hypothalamus in control or confined fish during this stress time-course (Fig. 3A, B, C).

In pituitary, MR is approx. 18 and 500 fold higher expressed compared to GR1 and GR2, respectively, and GR2 shows a 30-fold lower expression level compared to GR1 (Table 1). MR is the only $\mathrm{CR}$ in the pituitary which is affected by the confinement stress where it is down-regulated in confined fish relative to control fish (Fig. 4A, B, C). There is a significant decrease in MR levels from start of the confinement until day 1 , followed by a constant low level until day 4. Preconfinement MR levels are reached at day 7 (Fig. 4A).

There is no significant overall effect of confinement on GR1 and GR2 levels in the pituitary. However there is a recurrent up-regulation of these transcripts at day 7 where significantly higher GR1 and GR2 levels are observed in confined fish compared to control fish (Fig. 4B, C). There is an initial up-regulation of GR1 in pituitary in confined fish 4 hours after transfer, followed by a significant decrease and constant lower levels from 8 hours to 4 days after confinement until day 7 where a significant up-regulation of GR1, which exceed pre-confinement levels, is observed (Fig. 4B). During most of the confinement time-course GR2 levels are at the same or lower levels than day 0, up until day 7 where GR2 levels are up-regulated to exceed pre-confinement levels (Fig. 4C). In the interrenal gland GR1 is 3-fold higher expressed compared to MR and GR2, which are equally expressed (Table 1). GR2 are significantly down-regulated in confined fish compared to control fish, while there were no effect of confinement on MR and GR1 levels in the interrenal gland (Fig. 5A, B, C). Despite the lack of significant regulation compared to controls, MR mRNA levels in confined fish fluctuate significantly during the time-course. A nadir of MR is observed 4 hours after transfer to confinement cages, followed by a peak corresponding to pre-confinement levels at 8 hours. After another significant decrease, the MR level is stabilized at an intermediary expression level for the rest of the time-course (Fig. 5A). 


\subsection{Distribution of corticosteroid receptors in the pituitary gland.}

The distribution of GR1, GR2 and also MR expressing cells in the pituitary of trout appears very similar. The mRNA of GR1, GR2 and MR was observed in a number of scattered adenohypophyseal cells (Fig. 6) in all trout analyzed with no obvious differences between stressed and control fish (data not shown).

In order to start identifying the phenotype of the cells expressing glucocorticoid and mineralocorticoid receptors, we performed combined in situ hybridization and immunohistochemistry for GH, PRL and ACTH. We found few examples of cells expressing GR1 messengers and the ACTH peptide (Fig. 6A, A') and also GR1 mRNA and the GH peptide (Fig. 6B,B'). In a similar way, some GR2 expressing cells co-localize with both ACTH (Fig. 6C, C') and GH (Fig. 6D,D') immunopositive cells in particular in the rostral and proximal pars distalis.

Co-expression was also evident for the MR mRNA positive cells and ACTH cells (Fig. 6E, E') and GH cells (F, F') of trout adenohypophysis. Using specific anti-rtGR1 and anti-rtMR antibodies, we have been also able to show that GR1 and MR are expressed by the same pituitary cells (Fig. 7). Finally, no evident co-localization of GR1, GR2 or MR mRNA with prolactin cells was observed in the rostral pars distalis of trout adenohypophysis (data not shown). 


\section{Discussion}

This study aims to shed light on corticosteroid regulation of stress in fish with focus on the corticosteroid signalling system. Cortisol is a well-known stress hormone in fish and mammals, but it is still unclear through which of the three corticosteroid receptors found in teleost fish it exerts its action. Additionally, the role of the MR in stress endocrinology is becoming more evident in mammals (reviewed by de Kloet and Joëls, 2017), but is, so far, un-investigated in fish.

Thus we perform detailed description of plasma corticosteroid level and regulation of CR mRNAs in the HPI-axis during a confinement stress time-course study to shed light on the regulation and physiological significance of the cortisol signalling axis, consisting of cortisol, GR1, GR2 and MR, and the potential DOC-MR signalling axis in teleosts. As a significant effect of confinement stress on CR expressions was observed in the pituitary gland, we completed this experiment by demonstrating that $\mathrm{CR}$ receptors (GR1, GR2 and MR) are co-expressed in the ACTH cells located in the adenohypophysis. Overall, our data suggest involvement of GR1 and GR2 and also clearly show that MR is also implicated in regulation of HPI axis activity.

\subsection{Regulation of corticosteroid plasma levels}

In this study, cortisol was measured merely to establish the stressful conditions of the confinement. An increase in plasma cortisol levels during and/or after stress is well-known (reviewed by Mommsen et al., 1999 and Wendelaar Bonga 1997). Here we observe a small peak in plasma cortisol levels at 4 hours after transfer to confinement cages and a larger and longer sustained peak ranging from day 1 to day 3 which is in good agreement with Balm and Pottinger (1995) who used the same stress regime in rainbow trout and confirm that the confinement was indeed stressful. The up-regulation of DOC plasma levels presented in this paper is the first evidence suggesting a physiological role of DOC in fish stress endocrinology. However, the exact function and target tissues of this hormone still need to be clarified since there has been only very few studies investigating changes in plasma DOC levels in fish. So far, an increase in DOC levels was only observed in maturing male rainbow trout (Milla et al., 2008), which, together with the effects of DOC on spermatocrit values, led the authors to suggest a role for this hormone in regulation of spermiation in rainbow trout. Due to the mineralocorticoid-like association of DOC and MR from mammalian endocrinology, regulation of DOC in relation to osmoregulatory challenges has been 
investigated. However, no effect on DOC plasma levels were observed when exposing rainbow trout to salinity changes (Kiilerich et al., 2011) or mudskippers to terrestrial conditions (Sakamoto et al., 2011), which question the potential osmoregulatory function of this hormone (Takahashi and Sakamoto, 2013). However, the increase in DOC plasma levels reported in the present study may suggest that DOC might be a factor in regulation of the stress response in addition to the wellknown and-described stress hormone, cortisol. However, it is important to note that DOC plasma levels are in the range of 10 to $50 \mathrm{pg} / \mathrm{ml}$ thus 500 to 1000 times lower than cortisol plasma levels (Fig. 2A and 2B). As DOC is only 10 times more potent than cortisol on MR transactivation activity (Sturm et al., 2005), it is unlikely that such low levels of plasma DOC would regulate MR signalling pathway activity in stress response. However, co-localization of MR with 11-beta hydroxysteroid dehydrogenase type 2 (HSD-2) activity, converting cortisol to the inactive cortisone, might facilitate stress regulation of DOC through the MR. Such regulatory mechanism has been observed in mammalian brain (Roland et al., 1995; de Kloet and Joëls, 2017) but is so far not examined in fish, thus co-localization of MR and HSD-2 would be an interesting issue to clarify. Alternatively, DOC could be involved in the regulation of the HPI axis response to stress through its conversion into the neuroactive steroid THDOC ( $3 \alpha, 5 \alpha$-allotetrahydrodeoxycorticosterone) as shown in humans and rodents (see review by Brunton et al., 2016; Park et al., 2017). In brain and peripheral tissue DOC is converted to THDOC by enzymatic A-ring reduction by the $5 \alpha$-Reductase and $3 \alpha$-Hydroxysteroid oxidoreductase activity. THDOC lacks classical steroid hormone properties, but activates the post-synaptic inhibitory $\mathrm{GABA}_{\mathrm{A}}-(\gamma$-aminobutyric acid) receptor function on $\mathrm{CRH}$ expression (Reddy 2006) and suppress stress-induced HPA axis activity in rats (Budziszewska et al., 2010). Acute stress triggers a rapid and robust increase in circulating and brain levels of THDOC (Purdy et al., 1991). To our knowledge there are no reports on THDOC levels in fish but the $5 \alpha-$ Reductase enzyme has been located in lungfish brain and $5 \alpha$-Reductase activity is present in brain, spinal cord and pituitary in goldfish, toadfish and lamprey (Callard et al., 1980, Pasmanik \& Callard et al., 1985). The $3 \alpha$-hydroxysteroid oxidoreductase sequence can also be found in all ENSEMBL fish species and enzymatic activity has been reported in intestine and liver in channel catfish (Lou et al., 2002), suggesting that conversion of DOC to THDOC in teleost fish is possible. Furthermore, THDOC effect on $\mathrm{GABA}_{\mathrm{A}}$-receptor function in goldfish neurons has been demonstrated (Li and Yang, 2001). In this context, the prospective of DOC being involved in regulation of the stress response through its conversion into THDOC would deserve further studies. 


\subsection{Confinement stress and regulation of corticosteroid receptors.}

An important feature of cortisol as a stress hormone is its negative feedback control on HPI axis activity at the levels of hypothalamus, pituitary and interrenal gland. Generally, a down-regulation of the HPI axis reactivity is observed during chronic stress in fish (Barton, 2002, Barton et al., 2005, Madaro et al., 2015, Moltesen et al., 2016). However, the role of corticosteroid receptors in this feedback regulation of HPI axis still needs to be clarified.

\subsubsection{Hypothalamus}

Cortisol receptor proteins have been located in the hypothalamus and pituitary of salmonids using immunohistochemical studies (Teitsma et al., 1998, Carruth et al., 2000) which lead us to measure the regulation of the three corticosteroid receptors, MR, GR1 and GR2 in these tissues, and compare their levels of expression. In hypothalamus, GR2 showed the highest expression level, followed by GR1 and then MR (Table 1) an observation which is at variance with similar levels of GR1, GR2 and MR mRNA reported in carp hypothalamus and pituitary (Stolte et al., 2008a). However, in our study, we did not observe any significant change in the three receptors mRNA levels during short term (hours) and long term (up to 7 days) exposure to confinement. For acute stress exposure, these data obtained in the hypothalamus are in accordance with previous studies showing that acute stressors did not change GR1 expression levels in rainbow trout preoptic area (POA) (Alderman et al., 2012) or GR1 and GR2 expression in trout telencephalon (Moltesen et al., 2016). In carp, a 24h restraint stress did not modify significantly MR, GR1 and GR2 mRNA levels in the hypothalamus (Stolte et al., 2008a). However, in rainbow trout, a down regulation of MR after acute stress in the telencephalon but not in the hypothalamus was reported by Johansen et al. (2011) and a significant effect of acute stress on MR expression was observed in the trout telencephalon (Moltesen et al., 2016). Effects of chronic stress exposure has also been studied and, generally, these studies suggest also significant effects on receptors expression in the brain in association with changes in HPI axis reactivity: Thus, exposure of Atlantic salmon to unpredictable chronic stress resulted in a decreased expression of GR1, GR2 in the POA (Madaro et al., 2015) but repeated chasing stress had different effects on GR1 and GR2 expression in the POA whether experiments are done on parr or postsmolts (Madaro et al., 2016). In zebrafish, a high-grade chronic stress induced upregulation of brain GR and MR expressions whereas no significant effects were reported when applying a low-grade chronic stress (Pavlidis et al., 2015). In view of these above studies, our results showing no effects of acute or chronic confinement stress on corticosteroid receptors expressions may seem surprising. However, it is important to notice that we have limited our study to expression in the hypothalamus. 
We may also assume that response of receptor expression to stress may vary according to the intensity and severity of the stimuli.

\subsubsection{Pituitary}

A different picture of changes in corticosteroid receptor expression has been observed in the pituitary gland (Fig. 4). Whereas confinement has no effect $4 \mathrm{~h}$ and $8 \mathrm{~h}$ after start of the stress, chronic exposure to confinement leads to a significant decrease in MR expression, a pattern not observed for GR1 or GR2. Variable results have been reported in the literature: In carp, 24h restrain or cold transfer stress did not modify CR expression levels in the pituitary gland (Stolte et al., 2008a). In contrast, pituitary expressions of CRs in Atlantic salmon were up-regulated following unpredictable chronic stress whereas acute chasing stress only stimulates MR expression (Madaro et al., 2015). A stimulatory effect of an acute confinement stress on GR1, GR2 and MR expression has also been reported in salmon parr kept in freshwater but not in smolt reared in seawater where such stress had no effects (GR1 and GR2) or caused a down-regulation (MR) (Madaro et al., 2016). Overall, these studies suggest that, in salmonids, GRs and MR signalling pathway are involved to some extend in the regulation of pituitary functions after exposure to acute and/or chronic stressors. However, still variable responses can be observed depending on the nature of the stressors or the physiological state of the fish.

\subsubsection{Interrenal gland}

In this study there is no effect of a 7-day confinement stress on GR1 and MR levels but a general down-regulation of GR2 levels in confined fish compared to control. These results are partially in agreement with a previous study in Atlantic salmon reporting absence of effects of unpredictable chronic stress and acute stress on CR expression (Madaro et al., 2015). This is also somewhat discrepant with the slight but significant increase in GR1 but not GR2 levels in carp interrenal gland after a short term confinement stress (Stolte et al., 2008b). Moreover, cortisol injection resulted in increases of GR1 and GR2 in interrenal gland of sea bass and carp, respectively, within 6-24 hours (Stolte et al., 2009, Vazzana et al., 2010). Interestingly, the increase in GR1 levels in sea bass interrenal gland after cortisol injection was not accompanied by an increase in protein levels, which suggest an increased turn-over of proteins during stress (Vazzana et al., 2010). Differences in stress regime (chronic stress in this study vs. short term stress) and fish species may account for these discrepancies. 
In the interrenal gland, an ultra-short feedback loop of cortisol on interrenal function was suggested in teleost fish (Bradford et al., 1992; Rotllant et al., 2001). Cortisol-mediated decrease of cortisol release from the interrenal gland has been demonstrated in vivo and in vitro in flounder, sea bream and coho salmon (Bradford et al., 1992; Rotllant et al., 2000; Veillette et al., 2007) which was sensitive to GR antagonist (Veillette et al., 2007). In the present study, a general down-regulation of the GR2 levels in the interrenal gland suggests the need for less cortisol signalling through this receptor during stress. Application of confinement stress during 7 days leads to fluctuating expression of MR over time in confined fish but no clear overall significant effect of treatment. The rapid regulation of MR levels in the interrenal gland presented here suggests a possible role for this high affinity cortisol receptor in regulation of cortisol release in trout during early stages of the stress response. This is somewhat discrepant with the increase in MR in carp interrenal gland after 1 day of confinement as reported by Stolte et al. (2008b).

\subsection{Cellular localization of corticoid receptors in the pituitary gland.}

The clearest effects of confinement stress on regulation of CRs in the HPI axis are observed at the level of the pituitary where especially a down-regulation of MR expression is observed. In this context, we decided to complement our quantitative approach by analyzing the cellular localization of CR expressions in the pituitary gland in order to identify the main pituitary function(s) regulated by these receptors. Our data confirm localization of GR1 in adenohypophysial ACTH cells.

Moreover, we showed that GR1 and GR2 are co-expressed in this cell type (figure 6). Interestingly, we showed that MR transcripts are also expressed in ACTH cells and that GR1 and MR protein colocalize in the same adenohypophysis cell. These data clearly suggest that MR is a co-regulator comparable to GR1 and GR2 of ACTH cell activities in rainbow trout. Absence of expression of these receptors in PRL cells located aside ACTH cells in the adenohypophysis strengthens this conclusion. These data are in agreement with previous studies localizing in ACTH cells of GR1 expression in trout (Teitsma et al., 1998) and GR1 and GR2 in carp (Stolte et al., 2008a) or GR2 in tilapia (Aruna et al., 2015). In this last study, MR transcripts were also localized in corticotroph cells although it was not shown whether the same cells express GR transcripts. Our data bring clarification on this issue as we showed by immunochemical analysis co-expression of GR 1 and MR protein in the same adenohypohysial cells (Fig. 7). Our results not only confirmed HPI axis regulation at the level of pituitary by GRs but also indicate involvement of MR. Such regulation may occur through cortisol-MR signalling pathway as suggested above. However, it may also occur 
through MR-GR interaction where MR would have a dominant-negative role in cortisol mediated transcriptional activity (Kiilerich et al., 2015).

Finally, we also observed expression of the three CRs in GH pituitary cells (figure 6). These results are in agreement with a direct action of cortisol on GH release by pituitary cells (Uchida et al., 2004; Luo and McKeon, 1991). Moreover, chronic cortisol treatment in rainbow trout stimulates pituitary GH1 and GH2 transcription, consistent with the presence of glucocorticoid response elements in the GH1 and GH2 promotors (Yang et al., 1997). However, these effects are complex and dependant of exposure duration and dosage but also associated with a decrease of plasma GH levels (Madison et al., 2015). Demonstration of the expression of CR in GH cells confirms such direct regulation of these cells by cortisol but do not really clarify the complex regulation between pituitary GH expression and plasma hormone levels.

\section{Conclusion}

The results presented here suggest, for the first time, a function for DOC in the fish stress response. However, the low DOC levels compared to cortisol measured in the plasma do not favour an activity of DOC through MR receptors but rather suggest an activity of this GABAergic neurosteroid derivative, THDOC, on activation of the HPI axis. This hypothesis would deserve further studies including quantification of DOC in different brain parts in response to acute or chronic stress.

Furthermore we show differential contribution of the CRs in regulation and control of HPI axis activity following confinement stress. Judged by the variation of mRNA levels negative feedback regulation of cortisol release occurs on the level of the pituitary via MR and on the level of the interrenal gland via GR2. However, change in mRNA levels is not necessarily associated with similar change in protein levels (ex. Sathiyaa and Vijayan, 2003) and conclusions on this issue should be confirmed by measurement of CR protein levels during confinement stress. Finally, our study demonstrates that MR is co-expressed with GR1 and GR2 in ACTH cells, a result which suggests involvement of MR in regulation of HPI axis activity. It would be interesting now to decipher whether these receptors, having the same ligand (cortisol), have differential functions in the same cells and whether heterodimerization between GRs and MR (Kiilerich et al., 2011) is a physiological mechanism which regulate in rainbow trout response of ACTH cells to glucocorticoid. 


\section{References}

Alderman SL, McGuire A, Bernier NJ, Vijayan MM. 2012. Central and peripheral glucocorticoid receptors are involved in the plasma cortisol response to an acute stressor in rainbow trout. Gen Comp Endocrinol.176(1):79-85.

Aruna A, Nagarajan G, Chang CF. 2015. The acute salinity changes activate the dual pathways of endocrine responses in the brain and pituitary of tilapia. Gen Comp Endocrinol. 211:154-64

Auperin B, Baroiller JF, Ricordel MJ, Fostier A \& Prunet P. 1997. Effect of confinement stress on circulating levels of growth hormone and two prolactins in freshwater-adapted tilapia (Oreochromis niloticus). General and Comparative Endocrinology 108 35-44

Balm PH, Pottinger TG. 1995. Corticotrope and melanotrope POMC-derived peptides in relation to interrenal function during stress in rainbow trout (Oncorhynchus mykiss). Gen Comp Endocrinol. 1995 98(3):279-88.

Barton BA. 2002. Stress in fishes: a diversity of responses with particular reference to changes in circulating corticosteroids. Integr Comp Biol. 42(3):517-25.

Barton BA, Ribas L, Acerete, L, Tort L. 2005. Effects of chronic confinement on physiological responses of juvenile gilthead sea bream, Sparus aurata L., to acute handling. Aquaculture research 36(2) 172-179

Bernier NJ, Flik G, Klaren P. 2009. Regulation and contribution of the corticotropic, melanotropic and thyrotropic axes to the stress response in fishes. Fish Physiology 28, 235-311

Bradford CS, Fitzpatrick MS, Schreck CB. 1992. Evidence for ultra-short-loop feedback in ACTHinduced interregnal steroidogenesis in coho salmon: acute self-suppresion of cortisol secretion in vitro. Gen Comp Endocrinol. 87(2):292-9.

Brunton PJ. 2016. Neuroactive steroids and stress axis regulation: Pregnancy and beyond. J Steroid Biochem Mol Biol. 160:160-8.

Budziszewska B, Zając A, Basta-Kaim A, Leśkiewicz M, Steczkowska M, Lasoń W, Kaciński M. 2010. Effects of neurosteroids on the human corticotropin-releasing hormone gene. Pharmacol Rep. 62(6):1030-40.

Bury NR, Sturm A, Le Rouzic P, Lethimonier C, Ducouret B, Guiguen Y, Robinson-Rechavi M, Laudet V, Rafestin-Oblin ME, Prunet P. 2003. Evidence for two distinct functional glucocorticoid receptors in teleost fish. J Mol Endocrinol. 31(1):141-56.

Callard GV, Petro Z, Ryan KJ. 1980. Aromatization and 5 alpha-reduction in brain and nonneural tissues of a cyclostome, Petromyzon marinus. Gen Comp Endocrinol. 42(2):155-9.

Carruth LL, Jones RE, Norris DO. 2000. Cell density and intracellular translocation of lucocorticoid receptor-immunoreactive neurons in the kokanee salmon (Oncorhynchus nerka kennerlyi) brain, with an emphasis on the olfactory system. Gen Comp Endocrinol. 117(1):66-76.

Carruth LL, Jones RE, Norris DO. 2002. Cortisol and Pacific Salmon: A New Look at the Role of Stress Hormones in Olfaction and Home-stream Migration. Integr Comp Biol. 42(3):574-81.

Ducouret B, Tujague M, Ashraf J, Mouchel N, Servel N, Valotaire Y, Thompson EB. 1995. Cloning of a teleost fish glucocorticoid receptor shows that it contains a deoxyribonucleic acid-binding domain different from that of mammals. Endocrinology 136(9):3774-83.

Johansen IB, Sandvik GK, Nilsson GE, Bakken M, Overli O. 2011. Cortisol receptor expression differs in the brains of rainbow trout selected for divergent cortisol response, Comparative Biochemistry and Physiology, Part D, 6, 126-132 
Kiilerich P, Triqueneaux G, Christensen NM, Trayer V, Terrien X, Lombès M, Prunet P. 2015. Interaction between the trout mineralocorticoid and glucocorticoid receptors in vitro. Journal of Molecular Endocrinology. 55(1):55-68

Kiilerich P, Milla S, Sturm A, Valotaire C, Chevolleau S, Giton F, Terrien X, Fiet J, Fostier A, Debrauwer L, Prunet P. 2011. Implication of the mineralocorticoid axis in rainbow trout osmoregulation during salinity acclimation. J Endocrinol. 209(2):221-35.

de Kloet ER. 2003. Hormones, brain and stress. Endocr Regul. 37(2):51-68. Review.

de Kloet ER, Joëls M. 2017. Brain mineralocorticoid receptor function in control of salt balance and stress-adaptation. Physiol Behav. S0031-9384(16)30565-0.

Le Bail PY, Sumpter JP, Carragher JF, Mourot B, Niu PD, Weil C. 1991. Development and validation of a highly sensitive radioimmunoassay for chinooksalmon (Oncorhynchus tshawytscha) growth hormone. Gen Comp Endocrinol. 83(1):75-85.

Li P, Yang XL. 2001. Forskolin modulation of desensitization at GABA(A) and glycine receptors is not mediated by cAMP-dependent protein kinase in isolated carp amacrine-like cells. Pflugers Arch. 441(6):739-45.

Lou Z, Johnson JV, James MO. 2002. Intestinal and hepatic microsomal metabolism of testosterone and progesterone by a 3 alpha-hydroxysteroid dehydrogenase to the 3 alpha-hydroxy derivatives in the channel catfish, Ictalurus punctatus. J Steroid Biochem Mol Biol. 82(4-5):413-24.

Madaro A, Olsen RE, Kristiansen TS, Ebbesson LO, Nilsen TO, Flik G, Gorissen M. 2015.Stress in Atlantic salmon: response to unpredictable chronic stress. J Exp Biol. 218(Pt 16):2538-50.

Madaro A, Olsen RE, Kristiansen TS, Ebbesson LO, Flik G, Gorissen M. 2016. A comparative study of the response to repeated chasing stress in Atlantic salmon (Salmo salar L.) parr and post-smolts. Comp Biochem Physiol A Mol Integr Physiol. 192:7-16

Madison BN, Tavakoli S, Kramer S, Bernier NJ. 2015. Chronic cortisdol and reguklation of food intake and the endocrine growth axis in rainbow trout. J. Endocrinol. 226: 103-119.

Milla S, Terrien X, Sturm A, Ibrahim F, Giton F, Fiet J, Prunet P, Le Gac F. 2008. Plasma 11deoxycorticosterone (DOC) and mineralocorticoid receptor testicular expression during rainbow trout Oncorhynchus mykiss spermiation: implication with 17alpha, 20beta-dihydroxyprogesterone on the milt fluidity? Reprod Biol Endocrinol. 6(19).

Moltesen M, Laursen DC, Thörnqvist PO, Andersson MA, Winberg S, Höglund E. 2016. Effects of acute and chronic stress on telencephalic neurochemistry and gene expression in rainbow trout (Oncorhynchus mykiss). J Exp Biol. 219(Pt 24):3907-3914.

Mommsen TP, Vijayan MM, Moon TW. 1999. Cortisol in teleosts: dynamics, mechanisms of action, and metabolic regulation. Reviews in fish biology and fisheries. 9(3) 211-268

Park MH, Rehman SU, Kim IS, Choi MS, Yoo HH. 2017. Stress-induced changes of neurosteroid profiles in rat brain and plasma under immobilized condition. J Pharm Biomed Anal. 138:92-99.

Pasmanik M, Callard GV. 1985. Aromatase and 5 alpha-reductase in the teleost brain, spinal cord, and pituitary gland. Gen Comp Endocrinol. 60(2) 44-51.

Pavlidis M, Theodoridi A, Tsalafouta A. 2015. Neuroendocrine regulation of the stress response in adult zebrafish, Danio rerio. Prog Neuropsychopharmacol Biol Psychiatry. 60:121-31.

Pepels PP, Van Helvoort H, Wendelaar Bonga SE, Balm PH. 2004. Corticotropin-releasing hormone in the teleost stress response: rapid appearance of the peptide in plasma of tilapia (Oreochromis mossambicus). J Endocrinol. 180(3) 425-38.

Prunet P, Boeuf G, Houdebine LM. 1985. Plasma and pituitary prolactin levels in rainbow trout during adaptation to different salinities. J Exp Zool. 235(2):187-96. 
Prunet P, Sturm A, Milla S. 2006. Multiple corticosteroid receptors in fish: from old ideas to new concepts. Gen Comp Endocrinol. 147(1):17-23

Purdy RH, Morrow AL, Moore PH Jr, Paul SM. 1991. Stress-induced elevations of gammaaminobutyric acid type A receptor-active steroids in the rat brain. Proc Natl Acad Sci U S A. 88(10):4553-7.

Reddy DS. 2006. Physiological role of adrenal deoxycorticosterone-derived neuroactive steroids in stress-sensitive conditions. Neuroscience. 138(3):911-20. Review.

Roland BL, Krozowski ZS, Funder JW. 1995. Glucocorticoid receptor, mineralocorticoid receptors, 11 beta-hydroxysteroid dehydrogenase- 1 and -2 expression in rat brain and kidney: in situ studies. Mol Cell Endocrinol. 111(1):R1-7.

Rotllant, J., Arends, R.J., Mancera, J.M., Flik, G., Wendelaar Bonga, S.E., Tort, L. 2000. Inhibition of HPI axis response to stress in gilthead sea bream (Sparus aurata) with physiological plasma levels of cortisol. Fish physiology and biochemistry 23(1) 1 22

Sathiyaa R. and Vijayan MM. 2003. Autoregulation of glucocorticoid receptor by cortisol in rainbow trout hepatocytes. Amer. J. Physiol. 284: C1508-C1515.

Sakamoto T, Mori C, Minami S, Takahashi H, Abe T, Ojima D, Ogoshi M, Sakamoto H. 2011.Corticosteroids stimulate the amphibious behavior in mudskipper: potential role of mineralocorticoid receptors in teleost fish. Physiol Behav.104(5):923-8.

Servili A, Le Page Y, Leprince J, Caraty A, Escobar S, Parhar IS, Seong JY, Vaudry H, Kah O. 2011. Organization of two independent kisspeptin systems derived from evolutionaryancient kiss genes in the brain of zebrafish. Endocrinology. 2011 Apr;152(4):1527-40

Stolte EH, de Mazon AF, Leon-Koosterziel KM, Jesiak M, Bury NR, Sturm A, Savelkoul HF, van Kemenade BM, Flik G. 2008a. Corticosteroid receptors involved in stress regulation in common carp, Cyprinus carpio. J Endocrinol. 198(2):403-17.

Stolte EH, Nabuurs SB, Bury NR, Sturm A, Flik G, Savelkoul HF, Lidy Verburg-van Kemenade BM. 2008b. Stress and innate immunity in carp: corticosteroid receptors and proinflammatory cytokines. Mol Immunol. 46(1):70-9.

Stolte EH, Chadzinska M, Przybylska D, Flik G, Savelkoul HF, Verburg-van Kemenade BM. 2009. The immune response differentially regulates Hsp70 and glucocorticoid receptor expression in vitro and in vivo in common carp (Cyprinus carpio L.). Fish Shellfish Immunol. 27(1):9-16.

Sturm A, Bury N, Dengreville L, Fagart J, Flouriot G, Rafestin-Oblin ME, Prunet P. 2005. 11deoxycorticosterone is a potent agonist of the rainbow trout (Oncorhynchus mykiss) mineralocorticoid receptor. Endocrinology. 146(1):47-55.

Takahashi H, Sakamoto T. 2013. The role of 'mineralocorticoids' in teleost fish: relative importance of glucocorticoid signalling in the osmoregulation and 'central' actions of mineralocorticoid receptor. Gen Comp Endocrinol. 181:223-8.

Teitsma C, Lethimonier C, Tujague M, Anglade I, Saligaut D, Bailhache T, Pakdel F, Kah O, Ducouret B. 1998. Identification of potential sites of cortisol actions on the reproductive axis in rainbow trout. Comp Biochem Physiol C Pharmacol Toxicol Endocrinol. 119(3):243-9. Review.

Teitsma CA, Anglade I, Lethimonier C, Le Dréan G, Saligaut D, Ducouret B, Kah O. 1999.. Glucocorticoid receptor immunoreactivity in neurons and pituitary cells implicated in reproductive functions in rainbow trout: a double immunohistochemical study. Biol Reprod. 60(3):642-50. 
Teles M, Tridico R, Callol A, Fierro-Castro C, Tort L.2013. Differential expression of the corticosteroid receptors GR1, GR2 and MR in rainbow trout organs with slow release cortisol implants.Comp Biochem Physiol A Mol Integr Physiol.164(3):506-11.

Vazzana M, Vizzini A, Sanfratello MA, Celi M, Salerno G, Parrinello N. 2010. Differential expression of two glucocorticoid receptors in seabass (teleost fish) head kidney after exogeneous cortisol inoculation. Comp Biochem Physiol A Mol Integr Physiol. 157(1):49-54.

Veillette PA, Serrano X, Garcia MM, Specker JL. 2007. Evidence for the onset of feedback regulation of cortisol in larval summer flounder. Gen Comp Endocrinol 154(1-3), 105110

Wendelaar Bonga SE. 1997. The stress response in fish. Physiol Rev. 77(3):591-625.

Yang BY, Chan KM, Lin CM, Chen TT. 1997. Charcaterization of rainbow trout (Oncorhynchus mykiss) growth hormone 1 gene and the promoter region of growth hormone 2 gene. Arch. Biochem. Bioph. 340: 359-368.

Uchida K, Yoshikawa-Ebesu JS, Kajimura S, Yada T, Hirano T, Grau EG., 2004. In vitro effects of cortisol on the release and geen expression of prolactin andf growth hormone in the tyilapia, Oreochromis mossambicus. Gen. Comp. Endocrinol. 135: 396-408. 
Table 1:

\begin{tabular}{|l|l|l|l|l|l|l|l|l|l|}
\hline \multicolumn{6}{|l|}{ Absolute quantified pre-stress mRNA levels of MR, GR1 and GR2 in control fish } \\
\hline & Hypothalamus & Pituitary & \multicolumn{3}{l|}{ Interrenal gland } \\
\hline & Mean & SEM & $\begin{array}{l}\text { Significant } \\
\text { difference }\end{array}$ & Mean & SEM & $\begin{array}{l}\text { Significant } \\
\text { difference }\end{array}$ & Mean & SEM & $\begin{array}{c}\text { Significant } \\
\text { difference }\end{array}$ \\
\hline MR & 6,2 & 0,7 & C & 1974,2 & 137,0 & A & 3,0 & 0,6 & B \\
\hline GR1 & 32,6 & 4,0 & B & 114,2 & 15,5 & B & 9,2 & 1,8 & A \\
\hline GR2 & 51,8 & 5,0 & A & 3,9 & 0,5 & C & 3,3 & 0,6 & B \\
\hline
\end{tabular}

In vivo pre-stress mRNA levels of MR, GR1, and GR2 in rainbow trout hypothalamus, pituitary and interrenal gland. An absolute quantification was carried out for all target genes enabling a direct comparison between target gene expression levels. The mRNA levels are indicated as relative receptor level normalized to $18 \mathrm{~S}$. Different letters symbolize significant difference between values within a tissue $(\mathrm{p}<0.05)$ as determined by a one-way ANOVA followed by multiple $\mathrm{t}$-tests with Bonferroni corrections. 
Figure legends

Figure 1._Experimental outline of the stress time-course.

Figure 2. Changes in rainbow trout plasma DOC (A) and cortisol (B) during a seven day confinement stress time-course. There is an overall effect of confinement $(\mathrm{p}<0.0001$ for both DOC and cortisol) and time ( $\mathrm{p}<0.005$ and $\mathrm{p}<0.001$ for DOC and cortisol, respectively) with significant interaction only for cortisol $(\mathrm{p}<0.005)$. Values are means with SEM of 7-8 fish. Stars denote significant differences between control and confined groups $(\mathrm{p}<0.05)$. There is an overall effect of time $(\mathrm{p}<0.0001)$ on both DOC and cortisol levels in confined fish as determined by a one-way ANOVA. Values with no letters in common are significantly different, as determined by multiple ttests with Bonferroni correction.

Figure 3. Changes in rainbow trout hypothalamic mRNA levels of MR (A), GR1 (B) and GR2 (C) during confinement stress. There is no significant overall effect of confinement on either MR (A), GR1 (B) or GR2 (C). Values are means with SEM of 7-8 fish.

Figure 4. Changes in rainbow trout pituitary mRNA levels of MR (A), GR1 (B) and GR2 (C) during confinement stress. There is a significant overall effect of confinement $(p<0.05)$ for MR and a significant overall effect of time $(\mathrm{p}<0.05)$ for MR and GR1. There is significant interaction for MR $(\mathrm{p}<0.05)$, GR1 $(\mathrm{p}<0.01)$ and GR2 $(\mathrm{p}<0.05)$. Values are means with SEM of 7-8 fish. Stars denote significant differences between control and confined groups $(\mathrm{p}<0.05)$. There is an overall effect of time on MR $(\mathrm{p}<0.0003)$, GR1 ( $\mathrm{p}=0.001)$ and GR2 $(\mathrm{p}=0.01)$ levels in confined fish as determined by a one-way ANOVA. Values with no letters in common are significantly different, as determined by multiple t-tests with Bonferroni correction.

Figure 5. Changes in rainbow trout interrenal gland mRNA levels of MR (A), GR1 (B) and GR2 (C) during confinement stress. There is a significant overall effect of confinement $(p<0.005)$ for GR2 but not MR and GR1. There is no effect of time or interaction for all three target genes. Values are means with SEM of 7-8 fish. Stars denote significant differences between control and confined groups $(\mathrm{p}<0.05)$. There is an overall effect of time on MR $(\mathrm{p}=0.0017)$ and GR2 $(\mathrm{p}=0.05)$ levels in 
confined fish as determined by a one-way ANOVA. Values with no letters in common are significantly different, as determined by multiple t-tests with Bonferroni correction.

Figure 6. Localization of GR1, GR2 and MR mRNA in trout pituitary. In situ hybridization of GR1, GR2 and MR mRNA (red) co-localized with immunohistochemically detected ACTH or GH (green) in transverse sections of non-stressed rainbow trout pituitary. DAPI stain (blue) was used to visualize cell nuclei. A, C and E: Examples of GR1, GR2 and MR (red) expressing cells exhibiting immunoreactivity to ACTH (green). B, D, and F: Examples of GR1, GR2 and MR (red) expressing cells exhibiting immunoreactivity to GH (green). Arrowheads indicate example of co-localization. Yellow stars indicate the branches of neuropituitary in B, D, F, F'. A', B', C', D', E' and F' are magnifications of the boxed area in A, B, C, D, E and F, respectively. Scale bars $=50 \mu \mathrm{m}$.

Figure 7. Localization of GR1 and MR proteins in trout pituitary. Localization of rtMR (red, left panel) and rtGR1 (green, second panel) immunoreactivity using specific antibodies in transverse sections of non-stressed rainbow trout pituitary. The third panel represents the DAPI staining of nuclei (blue). The merged image (right panel) includes GR1 and MR specific images. Colocalization of MR and GR1 appears as orange cells. Scale bars $=25 \mu \mathrm{m}$. 
Experimental outline

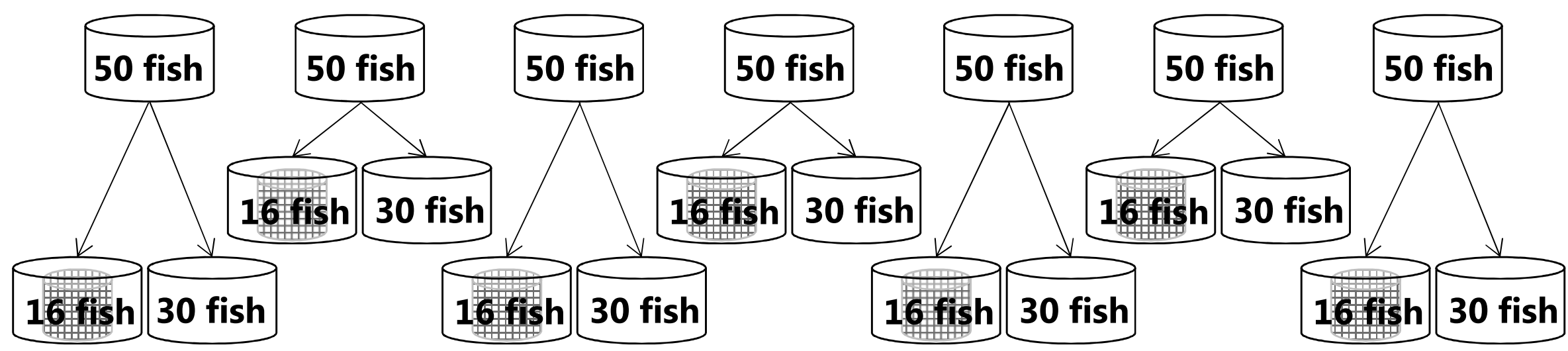

Sample eight fish from each tank at:

$4 \mathrm{~h}$

$8 h$

1d

$2 d$

$3 d$

$4 d$

$7 d$ 


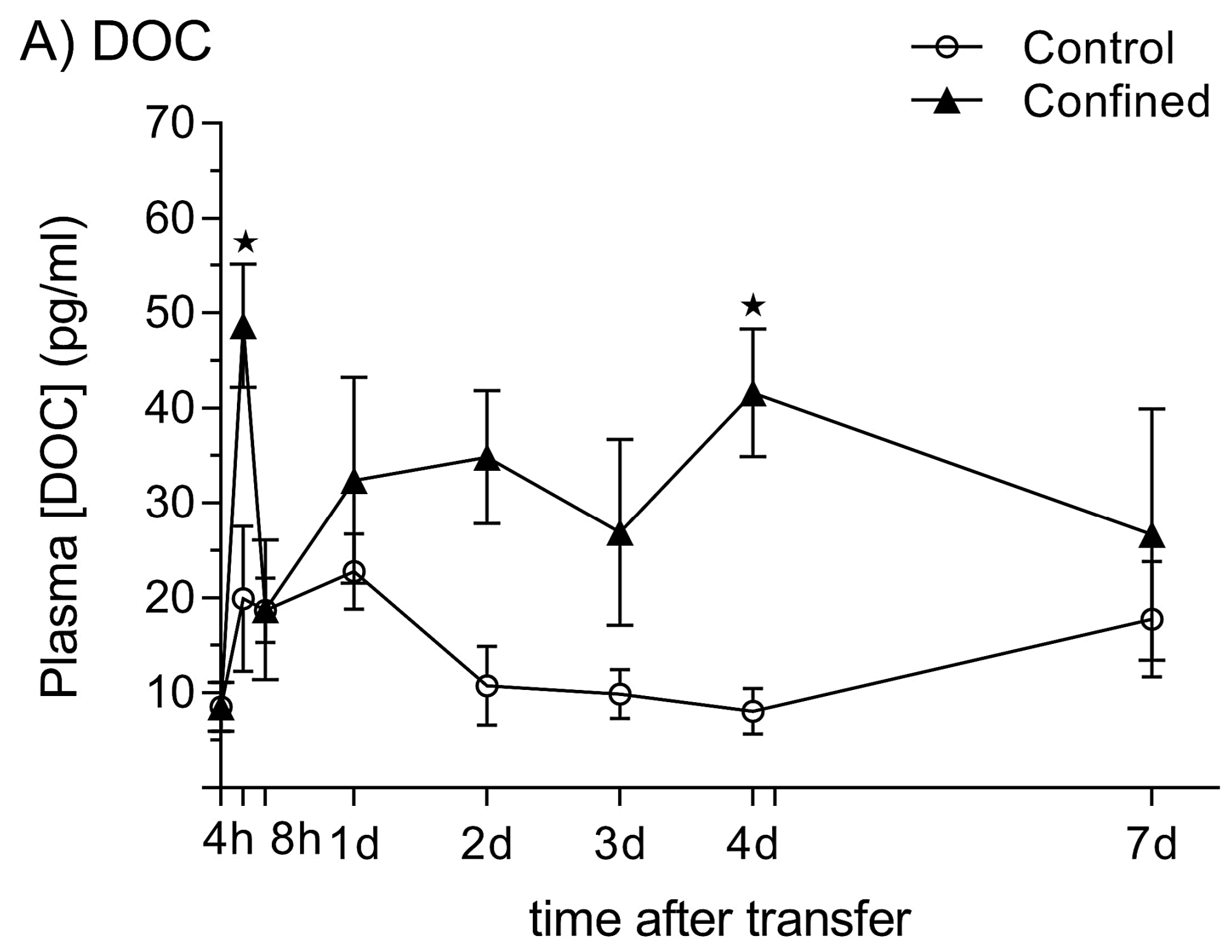

Two-way ANOVA:

One-way ANOVA

Time $p<0.05$

Control $p=0.13$

Confinement $p<0.0001$ Confinement $p=0.05$. 


\section{B) Cortisol}

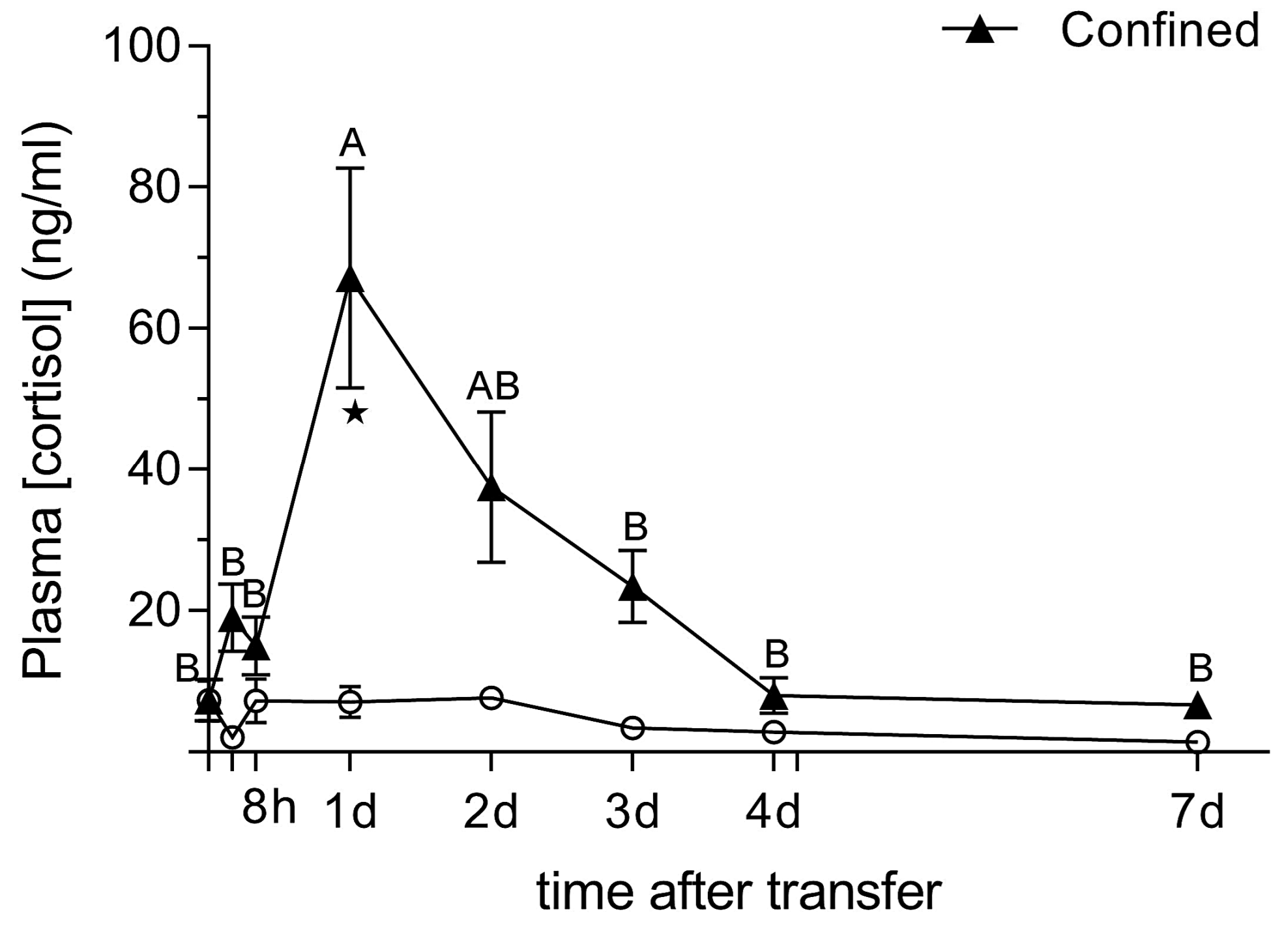

Two-way ANOVA:

Time $p<0.001$

Confinement $p<0.0001$ Confinement $p<0.0001$.
One-way ANOVA

Control $p=0.25$ 

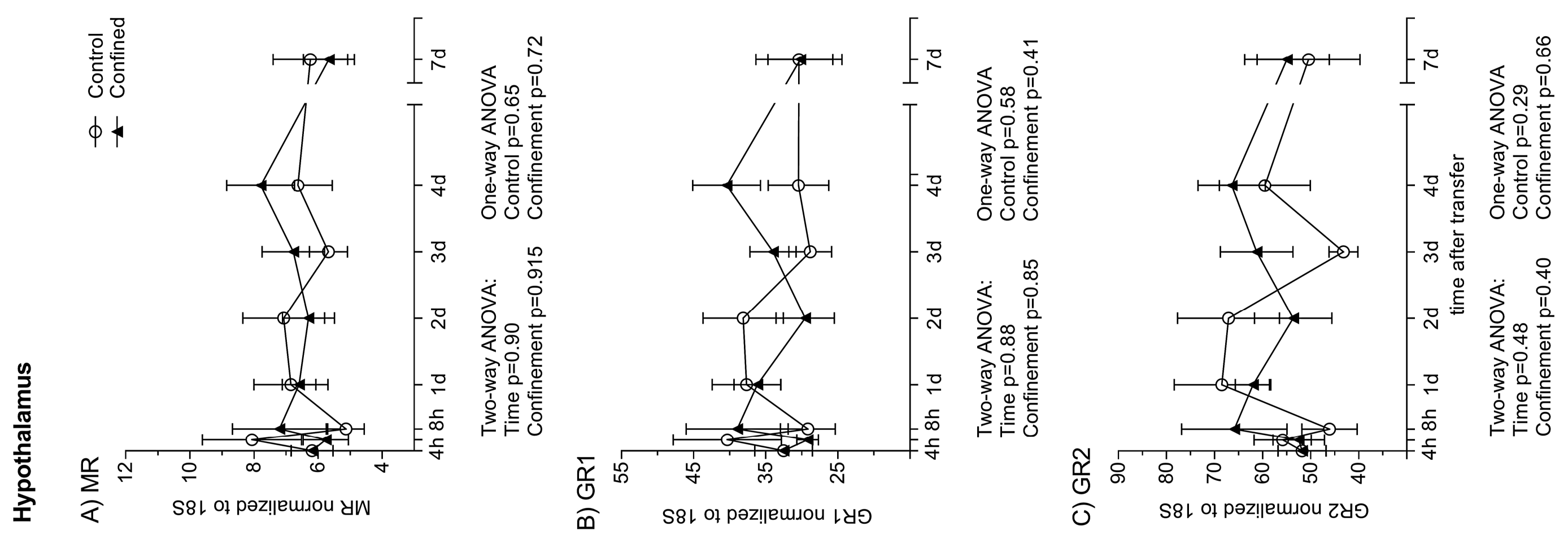

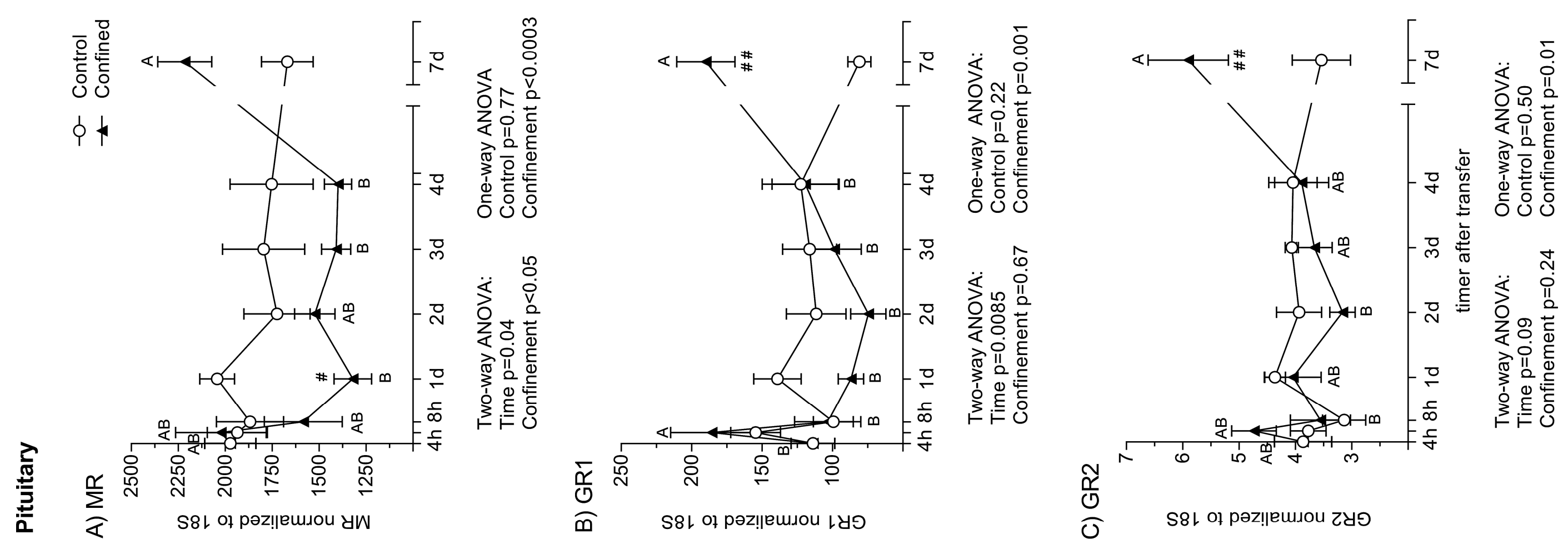

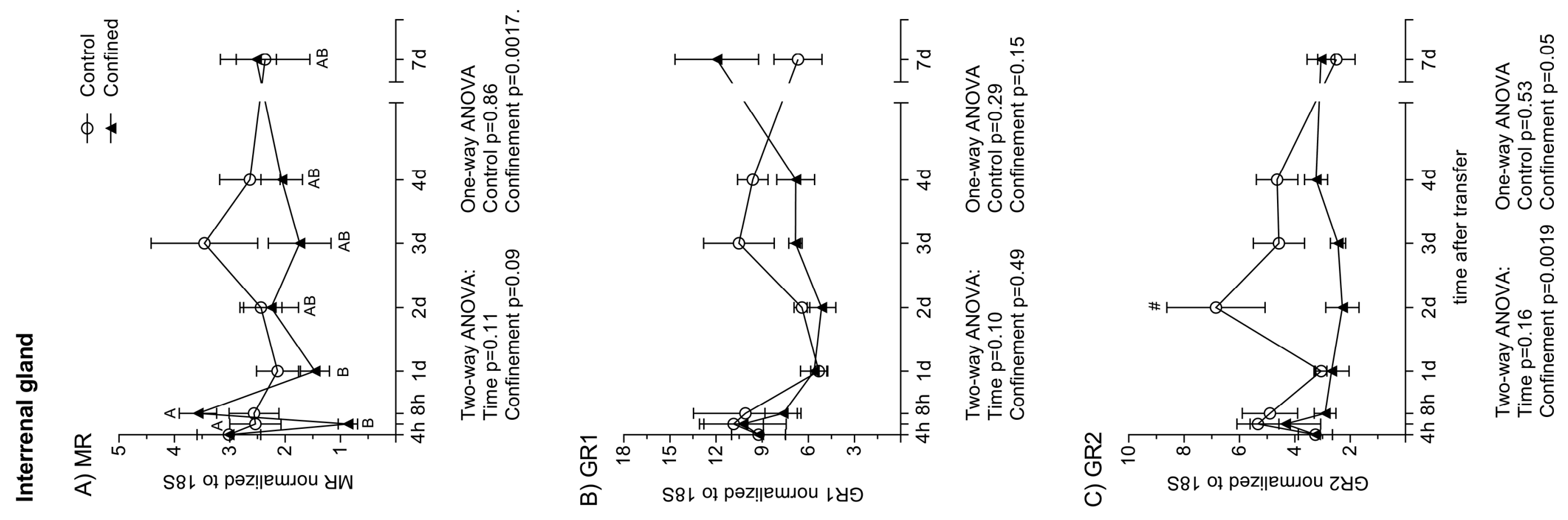


\section{Higthlights:}

We have measured plasma cortisol and DOC levels in rainbow trout exposed to confinement stress during 7 days.

We have measured glucocorticoid and mineralocorticoid receptors expression in hypothalamus, pituitary and interrenal and observed variable changes after confinement stress.

We demonstrate that corticosteroid receptors are co-expressed in pituitary ACTh and GH cells in rainbow trout. 